Check for updates

Cite this: RSC Adv., 2019, 9, 24875

Received 14th June 2019

Accepted 1st August 2019

DOI: 10.1039/c9ra04467a

rsc.li/rsc-advances

\section{A novel carboxylic-functional indole-based aerogel for highly effective removal of heavy metals from aqueous solution via synergistic effects of face- point and point-point interactions $\uparrow$}

\author{
Li Yang, (DD ab Peng Yang, ${ }^{a}$ Yuanchi Ma ${ }^{b}$ and Guanjun Chang (DD *ab \\ A new type of carboxylic-functional indole-based aerogel (CHIFA) has been successfully prepared via \\ a facile sol-gel technology, which possessed a highly effective removal of heavy metals from aqueous \\ solution through the synergistic effects of face-point and point-point interactions.
}

\section{Introduction}

In recent years, the health of human beings has been endangered by heavy metal ions, and the necessity for removal of heavy metals from aqueous solution is a very important issue due to their toxicity and bioaccumulation. ${ }^{1-4}$ Moreover, excessive intake of heavy metal ions, for example, $\mathrm{Ni}(\mathrm{II}),{ }^{5} \mathrm{Cu}(\mathrm{II}),{ }^{6}$ $\mathrm{Zn}(\mathrm{III})^{7}$ and $\mathrm{Cr}(\mathrm{III})^{8}$ is harmful to humans and other species. A wide range of technologies have been devised for the removal of metal ions from water including chemical precipitation, ${ }^{9}$ organic chelation, ${ }^{10}$ biological removal, ${ }^{11}$ ion-exchange,,${ }^{12,13}$ membrane separation ${ }^{14}$ and adsorption. ${ }^{15,16}$ Among these approaches, adsorption is found to be the most attractive way due to its advantages of relative simplicity, easy scale-up and high efficiency over a wide concentration range. ${ }^{17,18}$ Developing novel efficient, economical, green and environment-friendly adsorbents for heavy metal ions has been considered as an effective way to mitigate environmental deterioration. Aerogels have many specific features such as large surface area, high porosity, adjustable pore size, thermal and chemical stability, showing great advantages for the removal of heavy metals. ${ }^{19-22}$ However, the inherent physisorptive metal-adsorption mechanism makes them inevitably suffer from low adsorption capacity and efficiency hence severely hampers their practical applications. Recently, it was shown that porous materials

${ }^{a}$ State Key Laboratory for Environment-friendly Energy Materials, School of Material Science and Engineering, National Engineering Technology Center for Insulation Materials, Southwest University of Science and Technology, Mianyang, 621010, P. R. China.E-mail: gjchang@mail.ustc.edu.cn

${ }^{b}$ Department of Chemical and Biomolecular Engineering, University of Pennsylvania, Philadelphia, Pennsylvania, 19104, USA

$\dagger$ Electronic supplementary information (ESI) available: Details of preparation and characterization of the RFA, HIFA and CHIFA aerogels; SEM image, nitrogen adsorption-desorption isotherms and the pore size distribution of RFA and HIFAs; kinetics data and sorption data of CHIFA toward $\mathrm{Ni}^{2+}, \mathrm{Cu}^{2+}, \mathrm{Cr}^{3+}$ and $\mathrm{Zn}^{2+}$. See DOI: $10.1039 / \mathrm{c} 9 \mathrm{ra} 04467 \mathrm{a}$ containing multiple functional groups exhibit combined effects of each functional group that improve adsorption capacity and efficiency of heavy metals. ${ }^{18,23}$ The previous study of our team has found that the 4-HIFA containing hydroxyl and electronrich indole ring possessed strong affinity for heavy metals via the synergistic effects of complexation and cation- $\pi$ interactions ${ }^{23}$ however, the single functional group means that one hydroxyl can only complex one heavy metal, leading to less improvement in the heavy metals adsorption capacities for these indole-based aerogel materials. Therefore, to better utilize the cation- $\pi$ interactions for developing new heavy metals adsorbent with both excellent adsorption capacity and efficiency still remains attractive prospects and great challenge. A recent study indicated that carboxyl group can be considered as a functionality for removal of heavy metals by porous adsorbents. ${ }^{17}$

Inspired by those fascinating studies, we hypothesized that heavy metal ions adsorption capacity and efficiency can be improved by involving hydroxyl, carboxyl and indole groups in aerogel materials where multiple mechanisms work for heavy metals removal. In this work, a novel carboxylic-functional indole-based aerogel (CHIFA) (Schemes 1 and S4 $\dagger$ ) was tactfully designed and prepared through a simple and gentle gelation reaction where the bifunctional hydroxyl and carboxyl groups were set up at the two sides of the indole plane, respectively (the material preparation and characterization are

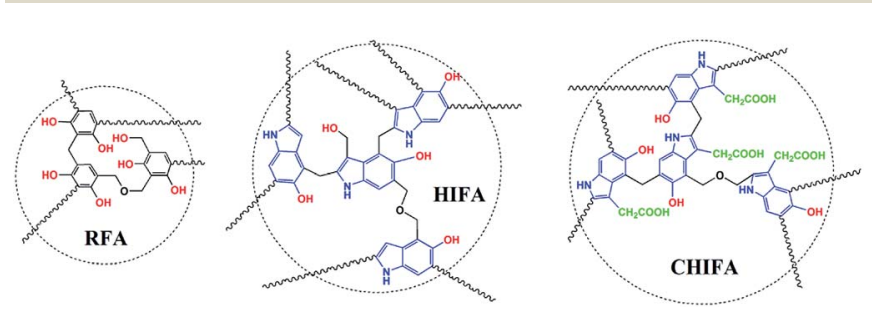

Scheme 1 Chemical structures of RFA, HIFA, and CHIFA aerogels. 
detailed in the ESI $\dagger$ ). On the one hand, the electron-rich $\pi$ indole plane is hopeful for attracting heavy metals via cation $-\pi$ interactions which belong to face-point interactions. On the other hand, the abundant phenolic-OH and carboxyl groups in the CHIFA aerogel provide more adsorption sites than that of the previously reported indole-based aeroge ${ }^{23}$ to metal ions via complexations, which belong to point-point interactions. It was expected that the synergistic effects of face-point and pointpoint interactions would endow the resulting carboxylicfunctional indole-based aerogel (CHIFA) remarkable heavy metals adsorption capacity and efficiency (Fig. 1).

The as-prepared CHIFA is a black, porous ultralight material, as shown in inset in Fig. 2a. For comparison, resorcinol-formaldehyde aerogel (RFA) and 5-hydroxyindole-formaldehyde aerogel (HIFA) were prepared as well (Schemes 1, S2 and S3†). RFA, HIFA and CHIFA aerogels were characterized by Fourier

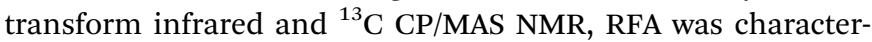
ized by Fourier transform infrared, and the results were in good agreement with the proposed structures (Fig. S4-S6†).

\section{Results and discussion}

We first quantified the porosity of aerogels by scanning electron microscopy (SEM) and sorption analysis using nitrogen as the sorbate molecule. Fig. 2a shows the scanning electron microscopy (SEM) image of CHIFA. The structure, which is very loose, contains mesopores and macropores. It consists of very small spheres, arranged in a filament-like structure to form a threedimensional matrix, pretty similar to the structure of the RF gel. ${ }^{24}$ As shown in Fig. S7, $\dagger$ RFA and HIFA have similar porous structures with minor differences in the size and shape of the aggregated particles. The porosity of aerogels were further quantified by sorption analysis using nitrogen as the sorbate molecule. The nitrogen adsorption-desorption isotherms of CHIFA measured at $-196{ }^{\circ} \mathrm{C}$ is shown in Fig. 2b, displaying a typical curve of type IV. ${ }^{25}$ There are hysteresis loops at relative pressures of 0.7-0.95, suggesting the presence of mesopores and macropores in the sample, ${ }^{26}$ in good agreement with those observed with the SEM technique (Fig. 2a). Correspondingly, the pore size is distributed at $43 \mathrm{~nm}$, as calculated by the nonlocal density functional theory method (NLDFT). The BET specific surface area and pore volume of CHIFA are estimated to be $143 \mathrm{~m}^{2} \mathrm{~g}^{-1}$ and $0.98 \mathrm{~cm}^{3} \mathrm{~g}^{-1}$, respectively (Fig. 2b). As shown in Fig. S7, $\dagger$ RFA and HIFA have similar nitrogen adsorptiondesorption isotherms and the pore size distribution (inset in

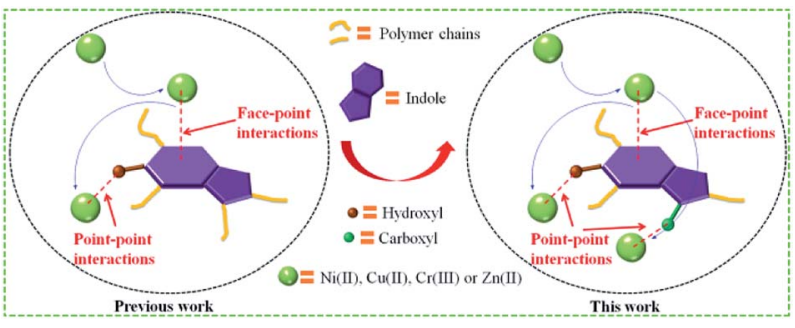

Fig. 1 Schematic illustration of heavy metals adsorption using CHIFA.
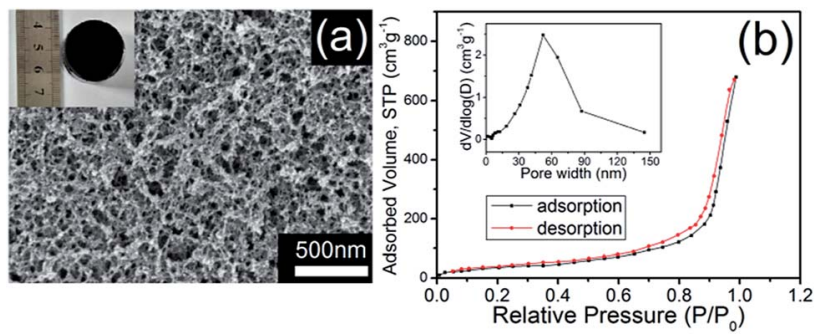

Fig. 2 (a) SEM image and photograph (inset), (b) nitrogen adsorptiondesorption isotherms and the pore size distribution (inset) of CHIFA.

Fig. S7 $\dagger$ ). The BET specific surface area of RFA and HIFA were estimated to be $118 \mathrm{~m}^{2} \mathrm{~g}^{-1}$ and $130 \mathrm{~m}^{2} \mathrm{~g}^{-1}$, the pore size was distributed at $52 \mathrm{~nm}$ and $46 \mathrm{~nm}$, respectively.

It was expected that the resulting CHIFA with $\mathrm{OH}-$ containing and $\mathrm{COOH}$-containing indole-based porous architecture may attract small heavy metal ions by the synergistic effects of facepoint and point-point interactions between the CHIFA network and heavy metals, which inspires us to investigate its heavy metal ions adsorption capacity.

Fig. S8 $\uparrow$ shows the dependences of the adsorption capacity for $\mathrm{Ni}^{2+}, \mathrm{Cu}^{2+}, \mathrm{Cr}^{3+}$ and $\mathrm{Zn}^{2+}$ on the $\mathrm{pH}$ value (2.0-6.0) over CHIFA. Fig. $\mathrm{S} 9 \dagger$ shows $\mathrm{Ni}^{2+}, \mathrm{Cu}^{2+}, \mathrm{Cr}^{3+}$ and $\mathrm{Zn}^{2+}$ adsorption recycled for 4 times.

The adsorption kinetics of the $\mathrm{Ni}^{2+}, \mathrm{Cu}^{2+}, \mathrm{Cr}^{3+}$ and $\mathrm{Zn}^{2+}$ ions by CHIFA was investigated in order to study adsorption rate and pathways of adsorption until equilibrium was reached. The results (Tables S1-S4 $\dagger$ ) and sorption kinetics curves (Fig. 3a) show rapid uptake rates and high removal efficiency. Within 2 min, the CHIFA achieved $\geq 97 \%$ removal rates and $K_{\mathrm{d}}$ values of $>10^{4} \mathrm{~mL} \mathrm{~g}^{-1}$ for $\mathrm{Ni}^{2+}$ (Table S1 $\dagger$ ) and $\mathrm{Cu}^{2+}$ (Table S2 $\dagger$ ). Within 5 min, the CHIFA achieved $\geq 98 \%$ removal rates and $K_{\mathrm{d}}$ values of $>10^{4} \mathrm{~mL} \mathrm{~g}^{-1}$ for $\mathrm{Ni}^{2+}$ (Table $\mathrm{S} 1 \dagger$ ) and $>10^{5} \mathrm{~mL} \mathrm{~g}^{-1}$ for $\mathrm{Cu}^{2+}$ (Table
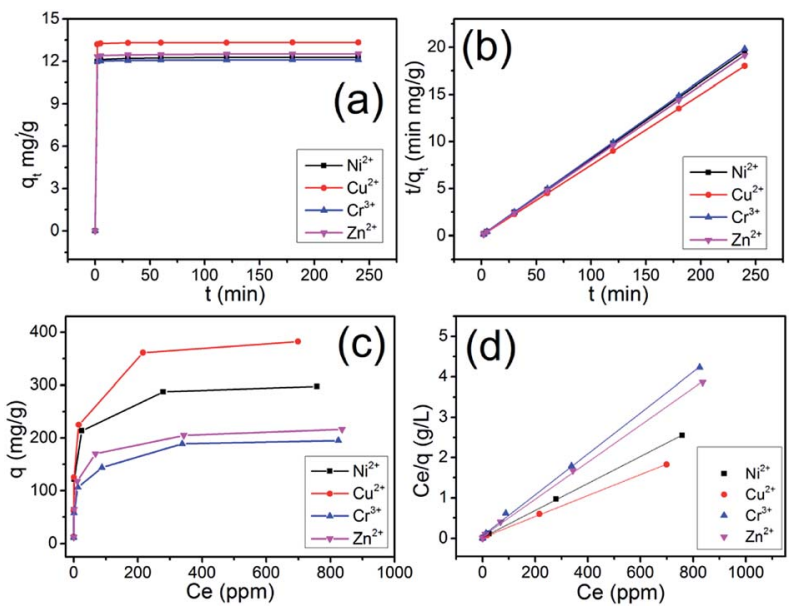

Fig. 3 Adsorption kinetics curves and sorption isotherms for $\mathrm{M}^{n+}\left(\mathrm{M}^{n+}\right.$ $=\mathrm{Ni}^{2+}, \mathrm{Cu}^{2+}, \mathrm{Cr}^{3+}, \mathrm{Zn}^{2+}$ ) by CHIFA: (a) sorption capacity $\left(q_{t}\right)$ with time, (b) pseudo-second-order kinetic plots for sorption, Langmuir equilibrium isotherms were derived from equilibrium concentration $\left(C_{\mathrm{e}}\right.$, ppm), plotted against the adsorption capacity (c) $q\left(\mathrm{mg} \mathrm{g}^{-1}\right)$ and (d) $C_{\mathrm{e}} /$ $q_{\mathrm{e}}\left(\mathrm{g} \mathrm{L}^{-1}\right)$. 
S2 $\dagger$ ). Within $30 \mathrm{~min}$, the CHIFA achieved $\geq 99 \%$ removal rates and $K_{\mathrm{d}}$ values of $>10^{5} \mathrm{~mL} \mathrm{~g}^{-1}$ for $\mathrm{Ni}^{2+}$ (Table $\mathrm{S} 1 \dagger$ ) and for $\mathrm{Cu}^{2+}$ (Table S2 $\dagger$ ). For the $\mathrm{Cr}^{3+}$ and $\mathrm{Zn}^{2+}$ ions (Tables $\mathrm{S} 3$ and $\mathrm{S} 4 \dagger$ ), the adsorption is slightly slow but still has a $98.35 \%$ and $98.66 \%$ removal rate in $30 \mathrm{~min}$, respectively. The adsorptions for all of the four ions reach equilibrium within $\sim 2$ min (Fig. 3a), which is more efficient than that of the previously reported indolebased aerogel. ${ }^{23}$

The removal rate can be determined in two different ways: pseudo-first-order and pseudo-second-order mechanisms, which were defined as follows: ${ }^{27}$

$$
\begin{gathered}
\text { Pseudo-first-order: } \ln \left(q_{\mathrm{e}}-q_{t}\right)=\ln q_{\mathrm{e}}-k_{1} \mathrm{t} \\
\text { Pseudo-second-order : } \frac{t}{q_{t}}=\frac{1}{k_{2} q_{\mathrm{e}}^{2}}+\frac{t}{q_{\mathrm{e}}}
\end{gathered}
$$

where $q_{\mathrm{e}}\left(\mathrm{mg} \mathrm{g}^{-1}\right)$ is the adsorbed amount per unit mass of adsorbent at equilibrium and $q_{t}\left(\mathrm{mg} \mathrm{g}^{-1}\right)$ is the adsorbed mass at time $t$, while $k_{1}\left(\mathrm{~min}^{-1}\right)$ and $k_{2}\left(\mathrm{~g} \mathrm{mg}^{-1} \mathrm{~min}^{-1}\right)$ are corresponding equilibrium rate constants. The $k_{1}$ value was obtained by plotting $\ln \left(q_{\mathrm{e}}-q_{t}\right)$ against $t$ and the $k_{2}$ by plotting $t / q_{t}$ against $t$. The linear relationship of $t / q_{t}$ versus $t$ was presented in Fig. $3 \mathrm{~b}$. From the kinetic parameters of $\mathrm{Ni}^{2+}, \mathrm{Cu}^{2+}, \mathrm{Cr}^{3+}$ and $\mathrm{Zn}^{2+}$ (Table $\mathrm{S} 5 \dagger)$, the calculated sorption capacities $\left(q_{\mathrm{e}, \text { cal }}\right)$ derived from the pseudo-second-order model are quite close to corresponding experimental values $\left(q_{\mathrm{e}, \mathrm{exp}}\right)$. The fit coefficient $\left(R_{2}\right)$ of 1 indicates the adsorption is well fitted with the pseudo-second-order kinetic model, suggesting a chemisorption process. ${ }^{28}$

Uptake capacity toward $\mathrm{Ni}^{2+}, \mathrm{Cu}^{2+}, \mathrm{Cr}^{3+}$ and $\mathrm{Zn}^{2+}$ by CHIFA from aqueous solutions was studied with the batch method at room temperature. The maximum adsorption capacity of the material was determined from an adsorption equilibrium study. The $\mathrm{Ni}^{2+}$ capture by CHIFA was found to increase successively with increasing concentration (10-1000 ppm, Table S6 $\dagger$ ). Over a wide range of the initial concentration (10-100 $\mathrm{ppm}$ ), the $\mathrm{Ni}^{2+}$ removal rates reached values of $>98 \%$, with the $K_{\mathrm{d}}^{\mathrm{Ni}}$ values ranging from $6.2 \times 10^{4}$ to $8.8 \times 10^{6} \mathrm{~mL} \mathrm{~g}^{-1}$. The maximum removal capacity $\left(q_{\mathrm{m}}\right)$ for $\mathrm{Ni}^{2+}$ reached $\sim 297.5 \mathrm{mg}$ $\mathrm{g}^{-1}$, which is higher than that of the previously reported indolebased aerogel. ${ }^{23}$ In addition, this is an exceptionally high capacity competing with those of the best absorbers such as PMCNa hybrid hydrogels $\left(224 \mathrm{mg} \mathrm{g}^{-1}\right)^{29}$ and polyvinyl alcohol/ corn starch hydrogel, ${ }^{30}$ for which adsorption capacities of various adsorbents are shown in Table S11. $\dagger$

We also checked the adsorption of the CHIFA material for $\mathrm{Cu}^{2+}$ in the range of concentrations $10 \mathrm{ppm}$ to $1000 \mathrm{ppm}$ (Table $\mathrm{S} 7 \dagger$ ), and found that there are $>99 \%$ removal rates in the initial concentration (10-100 ppm), and $\sim 382.5 \mathrm{mg} \mathrm{g}^{-1}$ maximum adsorption capacity, which is higher than that of the previously reported indole-based aerogel. ${ }^{23}$ In addition, this value is still very high compared to reported adsorbents (Table S11 $\dagger$ ). For $\mathrm{Cr}^{3+}$ and $\mathrm{Zn}^{2+}$, the maximum adsorption capacity is found to be relatively lower at $\sim 195.0 \mathrm{mg} \mathrm{g}^{-1}$ and $216.3 \mathrm{mg} \mathrm{g}^{-1}$ (Tables S8, and $\mathrm{S} 9 \dagger$ ), which is higher than that of the previously reported indole-based aerogel, ${ }^{23}$ however those value is still very high compared to reported adsorbents (Table S11 $\dagger$ ). In comparison to the reported materials as shown in Table S11, $\dagger$ the present
CHIFA demonstrates superior removal capacities for the target ions, which is attributed to the function of the introduced hydroxyl, carboxyl and indole groups in the sample, which is very helpful for the synergistic effects of face-point and pointpoint interactions between the CHIFA network and heavy metals.

A Langmuir isotherm is used to describe the experimental data of $\mathrm{Ni}^{2+}, \mathrm{Cu}^{2+}, \mathrm{Cr}^{3+}$ and $\mathrm{Zn}^{2+}$. In this model, the adsorbate moieties $\left(\mathrm{Ni}^{2+}, \mathrm{Cu}^{2+}, \mathrm{Cr}^{3+}, \mathrm{Zn}^{2+}\right)$ are assumed to undergo monolayer type coverage of the sorbent on an adsorbent surface. Once an adsorption site is occupied, no further adsorption can happen at the same site. The Langmuir isotherm model is listed as equation:

$$
q=q_{\mathrm{m}} \frac{b C_{\mathrm{e}}}{1+b C_{\mathrm{e}}}
$$

where $q\left(\mathrm{mg} \mathrm{g}^{-1}\right)$ is the equilibrium adsorption capacity of $\mathrm{Ni}^{2+}$, $\mathrm{Cu}^{2+}, \mathrm{Cr}^{3+}$ and $\mathrm{Zn}^{2+}$ adsorbed, $C_{\mathrm{e}}\left(\mathrm{mg} \mathrm{L}^{-1}\right)$ is the $\mathrm{Ni}^{2+}, \mathrm{Cu}^{2+}, \mathrm{Cr}^{3+}$ and $\mathrm{Zn}^{2+}$ concentration at equilibrium, $q_{\mathrm{m}}\left(\mathrm{mg} \mathrm{g}^{-1}\right)$ is the theoretical maximum sorption capacity. The equilibrium adsorption isotherms are shown in Fig. 3c, with the $\mathrm{Ni}^{2+}, \mathrm{Cu}^{2+}$, $\mathrm{Cr}^{3+}$ and $\mathrm{Zn}^{2+}$ equilibrium concentration ranging from 0.0008 to $836 \mathrm{ppm}$. The experimental data of uptake capacity for $\mathrm{Ni}^{2+}$, $\mathrm{Cu}^{2+}, \mathrm{Cr}^{3+}$ and $\mathrm{Zn}^{2+}$ are fitted well with the Langmuir isotherm model of eqn (3), see Fig. 3d. According to the Langmuir isotherm model, the expected capacity $q_{\mathrm{m}}$ of $298.5 \mathrm{mg} \mathrm{g}^{-1}$ for $\mathrm{Ni}^{2+}$, of $383.1 \mathrm{mg} \mathrm{g}^{-1}$ for $\mathrm{Cu}^{2+}$, of $196.9 \mathrm{mg} \mathrm{g}^{-1}$ for $\mathrm{Cr}^{3+}$ and of $217.4 \mathrm{mg} \mathrm{g}^{-1}$ for $\mathrm{Zn}^{2+}$, which are consistent with the experi-

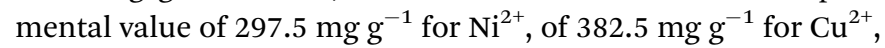
of $195.0 \mathrm{mg} \mathrm{g}^{-1}$ for $\mathrm{Cr}^{3+}$ and of $216.3 \mathrm{mg} \mathrm{g}^{-1}$ for $\mathrm{Zn}^{2+}$. The large correlation coefficient $\left(R^{2}>0.99\right)$ shows a good fit with the Langmuir isotherm, suggesting a monolayer adsorption ${ }^{31}$ on the CHIFA (Table S10†).

The $\mathrm{Cu}^{2+}$ adsorption capacity and efficiency in RFA, HIFA and CHIFA aerogels were evaluated by adsorption isotherms measurements. As shown in Fig. S10a, $\dagger$ the RFA, HIFA and CHIFA aerogels exhibits the highest $\mathrm{Cu}^{2+}$ sorption capacity of 158,265 and $361 \mathrm{mg} \mathrm{g}^{-1}$ in the initial concentration (10-500 ppm), respectively. As shown in Fig. S10b, $\dagger$ CHIFA is faster to reach equilibrium than HIFA and HIFA is faster to reach equilibrium than RFA with the same initial concentration of $10 \mathrm{ppm}$.

To identify the interaction between CHIFA samples and heavy metal ions during the adsorption process, FT-IR spectra of the CHIFA before and after $\mathrm{Ni}^{2+}, \mathrm{Cu}^{2+}, \mathrm{Cr}^{3+}$ and $\mathrm{Zn}^{2+}$ adsorption are compared (Fig. S10†). To elucidate the adsorption mechanism, the Density Functional Density (DFT) $)^{32-35}$ calculations were performed to investigate the interactions between CHIFA and $\mathrm{Cu}^{2+}$, the calculations were detailed in ESI. $\dagger$ The series of snapshots of $\mathrm{Cu}^{2+}$ adsorption are shown in Fig. 4 . For $\mathrm{Cu}^{2+}$-carboxyl complex, the optimized geometry is obtained when the carboxyl unit and $\mathrm{Cu}^{2+}$ forms $\mathrm{Cu}^{2+}$-carboxyl complex through point-to-point interaction, as shown in Fig. 4c, the corresponding energy is $44.86 \mathrm{~kJ} \mathrm{~mol}^{-1}$ (Fig. S12a†ं). The equilibrium conformation of $\mathrm{Cu}^{2+}$-indole is the electron-deficient $\mathrm{Cu}^{2+}$ and the indole ring forming face-to-point cation- $\pi$ configuration with the distance of $3.12 \AA$ (Fig. S12b $\dagger$ ), and the 


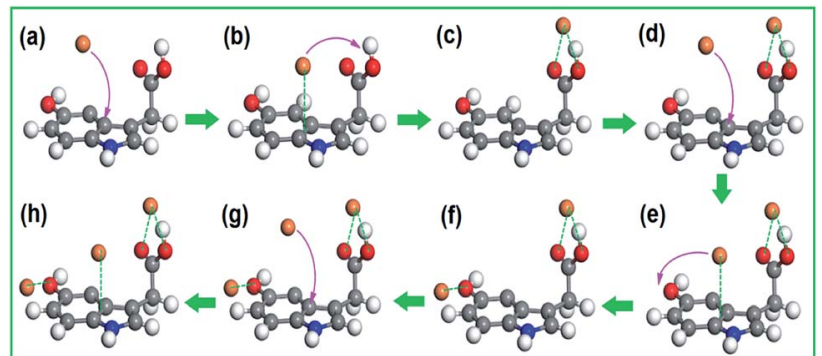

Fig. 4 DFT results to adsorb $\mathrm{Cu}^{2+}$ process involving synergistic faceto-point and point-to-point interactions. (a) $\mathrm{A} \mathrm{Cu}^{2+}$ is adsorbed on the face of a $\pi$-electron-rich indole group via the face-to-point interaction. (b) The cation $-\pi$ structure is obtained. (c) The desorbed $\mathrm{Cu}^{2+}$ can be adsorbed by an adjacent carboxyl group through point-to-point interaction. (d) Second $\mathrm{Cu}^{2+}$ comes close to the indole ring. (e) The desorbed $\mathrm{Cu}^{2+}$ can be adsorbed by the adjacent hydroxyl group through point-to-point interaction. (f) A stable conformation is formed. (g) Third $\mathrm{Cu}^{2+}$ comes close to the indole ring. (h) Three $\mathrm{Cu}^{2+}$, CHIFA formed a stable system. The white, gray, blue, and red spheres represent hydrogen, carbon, nitrogen, and oxygen atoms, respectively.

computational binding energy is $32.53 \mathrm{~kJ} \mathrm{~mol}^{-1}$ (Fig. S12b $\dagger$ ). Additionally, hydroxyl group can adsorb $\mathrm{Cu}^{2+}$ through point-topoint interaction (Fig. S12c $\dagger$ ). However, adsorbing of mobile $\mathrm{Cu}^{2+}$ by carboxyl and hydroxyl units is difficult because of the point-to-point binding area by only two atomistic sites. On the contrary, $\mathrm{Cu}^{2+}$ can be easily and rapidly adsorbed on indole ring due to its relatively large binding area through face-to-point cation $-\pi$ interaction ${ }^{23,36}$ (Fig. 4b). Adsorption and desorption occur simultaneously, driven by thermal fluctuation. Once desorption occurs, the starting speed should be slow down compared with the bulk, leading to a high probability to be adsorbed by an adjacent carboxyl and hydroxyl units. The complexation of $\mathrm{Cu}^{2+}$ and carboxyl and hydroxyl, therefore, can be facilitated with the help of an adjacent indole, forming $\mathrm{Cu}^{2+}$ carboxyl and $\mathrm{Cu}^{2+}$-hydroxyl complex more easily and efficiently.

\section{Conclusions}

In summary, we have rationally designed a new type of carboxylic-functional indole-based aerogel (CHIFA) that is easily prepared via a facile sol-gel technology involving phenolic resin-inspired chemistry, and we have demonstrated that the aerogel could be used as a high effective extraction material for heavy metals from aqueous solution through the synergistic effects of face-point and point-point interactions between the CHIFA network and heavy metals.

\section{Conflicts of interest}

There are no conflicts to declare.

\section{Acknowledgements}

This work was financially supported by the National Natural Science Foundation of China (No. 21504073, 21202134, 11447215). We thank the Southwest Computing Center of the
China Academy of Physics Engineering for their support of computer simulation.

\section{Notes and references}

1 R. P. Schwarzenbach, B. I. Escher, K. Fenner, T. B. Hofstetter, C. A. Johnson, U. V. Gunten and B. Wehrli, Science, 2006, 313, 1072.

2 J. O. Nriagu and J. M. Pacyna, Nature, 1988, 333, 134.

3 L. Liu, X. Guo, R. Tallon, X. Huang and J. Chen, Chem. Commun., 2017, 53, 881.

4 P. Yang, L. Yang, J. Yang, X. Luo and G. Chang, High Perform. Polym., 2019, 31, 238.

5 L. Wang, D. Hu, X. Kong, J. Liu, X. Li, K. Zhou, H. Zhao and C. Zhou, Chem. Eng. J., 2018, 346, 38.

6 M. R. Awual, I. M. M. Rahman, T. Yaita, M. A. Khaleque and M. Ferdows, Chem. Eng. J., 2014, 236, 100.

7 Y. Shi, T. Zhang, H. Ren, A. Kruse and R. Cui, Bioresour. Technol., 2018, 247, 370.

8 X. J. Hu, J. S. Wang, Y. G. Liu, X. Li, G. M. Zeng, Z. L. Bao, X. X. Zeng and F. Long, J. Hazard. Mater., 2011, 185, 306.

9 R. Zarrougui, R. Mdimagh and N. Raouafi, J. Hazard. Mater, 2018, 342, 464.

10 T. Saito, S. Brown, S. Chatterjee, J. Kim, C. Tsouris, R. T. Mayes, L. J. Kuo, G. Gill, Y. Oyola and C. J. Janke, J. Mater. Chem. A, 2014, 2, 14674.

11 L. S. Oliveira, A. S. Franca, T. M. Alves and S. D. Rocha, J. Hazard. Mater., 2008, 155, 507.

12 M. Kasanmascheff, W. Lee, T. U. Nick, J. A. Stubbe and M. Bennati, Chem. Sci., 2016, 7, 2170.

13 A. Ma, A. Abushaikha, S. J. Allen and G. McKay, Chem. Eng. J., 2019, 358, 1.

14 I. K. Moideen, A. M. Isloor, A. A. Qaiser, A. F. Ismail and M. S. Abdullah, Korean J. Chem. Eng., 2018, 35, 1281.

15 G. Zhao, X. Huang, Z. Tang, Q. Huang, F. Niu and X. Wang, Polym. Chem., 2018, 9, 3562.

16 H. Chen, J. Lin, N. Zhang, L. Chen, S. Zhong, Y. Wang, W. Zhang and Q. Ling, J. Hazard. Mater., 2018, 345, 1.

17 B. Aguila, Q. Sun, J. A. Perman, L. D. Earl, C. W. Abney, R. Elzein, R. Schlaf and S. Ma, Adv. Mater., 2017, 29, 1700665.

18 B. Hayati, A. Maleki, F. Najafi, H. Daraei, F. Gharibi and G. McKay, J. Hazard. Mater., 2017, 336, 146.

19 K. Kadirvelu, J. Goel and C. Rajagopal, J. Hazard. Mater., 2008, 153, 502.

20 P. Rana, N. Mohan and C. Rajagopal, Water Res., 2004, 38, 2811.

21 A. K. Meena, G. Mishra, P. Rai, C. Rajagopal and P. Nagar, J. Hazard. Mater., 2005, 122, 161.

22 S. M. Alatalo, F. Pileidis, E. Mäkilä, M. Sevilla, E. Repo, J. Salonen, M. Sillanpää and M.-M. Titirici, ACS Appl. Mater. Interfaces, 2015, 7, 25875.

23 P. Yang, L. Yang, Y. Wang, L. Song, J. Yang and G. Chang, J. Mater. Chem. A, 2019, 7, 531.

24 O. Czakkel, K. Marthi, E. Geissler and K. László, Microporous Mesoporous Mater., 2005, 86, 124.

25 G. Leofanti, M. Padovan, G. Tozzola and B. Venturelli, Catal. Today, 1998, 90, 207. 
26 X. Zhu, S. M. Mahurin, S. H. An, C. L. Dothanh, C. Tian, Y. Li, L. W. Gill, E. W. Hagaman, Z. Bian and J. H. Zhou, Chem. Commun., 2014, 50, 7933.

27 S. Azizian, J. Colloid Interface Sci., 2004, 276, 47.

28 T. Liu, M. Yang, T. Wang and Q. Yuan, Ind. Eng. Chem. Res., 2012, 51, 454.

29 P. Spasojevic, V. Panic, M. Jovic, J. Markovic, C. van Roost, I. Popovic and S. Velickovic, J. Mater. Chem. A, 2016, 4, 1680. 30 M. N. K. Chowdhury, A. F. Ismail, M. D. H. Beg, G. Hegde and R. J. Gohari, New J. Chem., 2015, 39, 5823.
31 A. Farrukh, A. Akram, A. Ghaffar, S. Hanif, A. Hamid, H. Duran and B. Yameen, ACS Appl. Mater. Interfaces, 2013, 5,3784 .

32 G. Chang, Z. Shang, Y. Tao and L. Yang, J. Mater. Chem. A, 2016, 4, 2517.

33 W. Wei, G. Chang, Y. Xu and L. Yang, J. Mater. Chem. A, 2018, 6, 18794.

34 K. Wang, L. Yang, W. Wei, L. Zhang and G. Chang, J. Membr. Sci., 2018, 549, 23.

35 Y. Li, L. Yang, M. Du and G. Chang, Analyst, 2019, 144, 1260. 36 G. Chang, Y. Wang, C. Wang, Y. Li, Y. Xu and L. Yang, Chem. Commun., 2018, 54, 9785. 